\title{
EVALUASI KINERJA BOILER UNIT 2 PLTU 2 BANTEN-LABUAN MENGGUNAKAN METODA LANGSUNG DAN TIDAK LANGSUNG
}

\author{
Maridjo, Kholiq Hernawan dan, Bagus Dwi Nurtanto \\ Jurusan Teknik Konversi Energi - Politeknik Negeri Bandung \\ E-mail: mmaridjo@gmail.com ; bagusenergi08@yahoo.co.id
}

\begin{abstract}
Abstrak
Boiler pada sistem Pembangkit Listrik Tenaga Uap (PLTU) merupakan komponen utama yang fungsinya sangat vital. Kinerja boiler khususnya efisiensi adalah parameter penting yang harus diperhatikan,karena merupakan jaminan dalam pengoperasian boiler. Berdasarkan standar disainnya, boiler di PLTU 2 Banten-Labuan memiliki efisiensi sebesar 93,1\% pada beban maksimum, dan efisiensi hasil komisioning pada tahun 1994 yaitu sebesar 87,21\% pada beban maksimum. Berdasarkan hasil pengujian yang dilakukan pada tahun 2011dengan menggunakan metode langsung diperoleh efisiensi boiler sebesar $87,3 \%$ sedangkan dengan metode tidak langsung adalah $85,05 \%$ pada beban maksimum. Dengan demikian efisiensi boiler tersebut masih cukup baik.
\end{abstract}

Kata kunci : PLTU, kinerja boiler, metode langsung, metode tidak langsung

\section{PENDAHULUAN}

Energi listrik merupakan energi yang sekarang ini sangat dibutuhkan oleh semua orang untuk memenuhi dan menunjang kebutuhan hidup. Indonesia sebagai negara berkembang dengan teknologi dan ilmu pengetahuannya yang semakin maju mau tidak mau kebutuhan energi listriknya juga meningkat, sedangkan pusat-pusat pembangkit tenaga listrik yang ada belum mampu memenuhi kebutuhan masyarakat secara baik. Salah satu program pemerintah untuk memenuhi kebutuhan energi listrik tersebut adalah dengan proses PPDE (Program Percepatan Diversifikasi Energi) $10.000 \mathrm{MW}$.

PLTU 2 Banten-Labuan 2x300 MW dengan bahan bakar batubara yang memiliki nilai kalori rendah (4.250 kalori) sesuai dengan peraturan RI Nomor 71 Tahun 2006, merupakan salah satu pembangkit listrik yang dibangun dalam rangka program percepatan tersebut.

Sebagai suatu sistem besar PLTU memiliki komponen dan sistem pendukung yang menunjang operasinya. Komponen utama dari PLTU adalah boiler, turbin uap, kondensor, pompa, dan generator. Sedangkan Sistem pendukung dari PLTU yaitu sistem aliran fluida, sistem aliran uap, sistem aliran udara, sistem gas buang, dan sistem coal handling.
Boiler atau ketel uap yaitu suatu bejana tertutup dimana panas pembakaran dari bahan bakar diserap oleh air sehingga air berubah menjadi uap/steam. Energi panas yang digunakan untuk mengubah air menjadi uap didapatkan dari suatu sumber panas, seperti bahan bakar (padat, cair, dan gas), energi listrik, sisa proses kimia, dan energi nuklir.

Boiler sebagai salah satu komponen utama dari pembangkit listrik tenaga uap yang berfungsi menghasilkan uap sebagai fluida kerja yang menggerakan turbin memiliki perlengkapan utama seperti furnacel ruang bakar dan steam drum yang memungkinkan boiler dapat bekerja. Selain itu boiler juga didukung oleh cerobong asap dengan sistem tarikan asapnya. sehingga ruang bakar dapat bekerja optimal. Perlengkapan lain seperti pemanas uap lanjut, pemanas udara pembakaran, dan pemanas awal air umpan boiler berguna untuk menaikan kinerja boiler secara umum.

Kinerja dari boiler akan menurun seiring dengan semakin lamanya waktu operasi. Kinerja boiler seperti efisiensi dapat menurun yang diakibatkan oleh buruknya proses pembakaran, kotornya permukaan penukar panas, dan kurang baiknya operasi serta perawatan. Untuk boiler yang baru sekalipun, kinerja yang buruk dapat terjadi disebabkan oleh rendahnya kualitas bahan bakar maupun kualitas air umpan. 
Oleh karena itu diperlukan metode perhitungan kinerja boiler khususnya efisiensi guna mengetahui baik atau buruk kinerja suatu boiler, dan diketahui dari sisi mana kinerja tersebut menurun sehingga dapat ditentukan peluang-peluang yang harus dilakukan untuk meningkatkan atau mengembalikan kinerjanya.

\section{METODOLOGI}

Terdapat dua metode pengkajian efisiensi boiler yang mengacu pada british standard, BS 845:1987 dan USA standard ASME PTC 4-1 (UNEP/www.energyeficiencyasia.org):

1. Metode langsung: energi yang didapat dari fluida kerja (air dan uap) dibandingkan dengan energi yang terkandung dalam bahan bakar boiler.

2. Metode tidak langsung: efisiensi merupakan perbedaan antara kehilangan panas dan energi yang masuk.

Efisiensi termis boiler didefinisikan sebagai "persen energi (panas) masuk yang digunakan secara efektif pada steam yang dihasilkan"

\section{Metode langsung}

Dikenal juga sebagai 'metode input-output' karena dalam kenyataannya metode ini hanya memerlukan keluaran/ output (uap) dan panas masuk/ input (bahan bakar) untuk menghitung efisiensi.

Efisiensi ini dapat dihitung dengan menggunakan rumus:

$$
\begin{aligned}
\text { Efisiensi Boiler }(\eta) & =\frac{\text { Panas Keluar }}{\text { Panas Masuk }} \times 100 \\
\text { Efisiensi Boiler }(\eta) & =\frac{\text { muap X (huap }- \text { hair) }}{\text { mbb X GCV }} \\
& \times 100
\end{aligned}
$$

Parameter yang digunakan untuk perhitungan efisiensi boiler dengan metode langsung adalah:

1. Jumlah steam yang dihasilkan per jam $\left(\mathrm{m}_{\text {uap }}\right)(\mathrm{kg} / \mathrm{jam})$;

2. Jumlah bahan bakar yang digunakan per jam (mbb) (kg/jam);
3. Tekanan kerja $\left(\mathrm{kg} / \mathrm{cm}^{2}\right)$ dan suhu lewat panas $\left({ }^{\circ} \mathrm{C}\right)$, jika ada;

4. Suhu air umpan $\left({ }^{\circ} \mathrm{C}\right)$;

5. Jenis bahan bakar dan nilai panas kotor bahan bakar (GCV) (kkal/kg bahan bakar)

Dimana:

- $\mathrm{h}_{\text {uap }}=$ Entalpi steam jenuh (kkal/kg steam)

- $\mathrm{h}_{\text {air }}=$ Entalpi air umpan (kkal/kg air)

\subsubsection{Metode tidak langsung}

Metode tidak langsung juga dikenal dengan metode kehilangan panas. Efisiensi ini dapat dihitung dengan mengurangkan bagian kehilangan panas sebagai berikut:

$(\eta)=100 \%-(q 1+q 2+q 3+q 4+q 5+q 6+q 7)$

$\operatorname{Dimana}(q 1+q 2+q 3+q 4+q 5+q 6+q 7)$ adalah kehilangan panas yang terjadi dalam boiler yang diakibatkan oleh:

1. Gas cerobong yang kering

2. Penguapan air yang terbentuk karena $\mathbf{H}_{2}$ dalam bahan bakar

3. Penguapan kadar air dalam bahan bakar

4. Adanya kadar air dalam udara pembakaran

5. Bahan bakar yang tidak terbakar dalam abu terbang/fly ash

6. Bahan bakar yang tidak terbakar dalam abu bawah / bottom ash

7. Radiasi dan kehilangan lain yang tidak terhitung

Kehilangan yang diakibatkan oleh kadar air dalam bahan bakar dan yang disebabkan oleh pembakaran hidrogen tergantung pada bahan bakar tersebut, dan tidak dapat dikendalikan dalam perancangan.

Data yang diperlukan untuk perhitungan efisiensi boiler dengan menggunakan metode tidak langsung adalah:

1. Analisis ultimate bahan bakar $\left(\mathrm{H}_{2}, \mathrm{O}_{2}, \mathrm{~S}\right.$, C, kadar air, kadar abu)

2. Persentase oksigen atau $\mathrm{CO}_{2}$ dalam gas buang

3. Suhu gas buang $\left({ }^{\circ} \mathrm{C}\right)\left(\mathrm{T}_{\mathrm{f}}\right)$ 
4. Suhu ambien $\left({ }^{\circ} \mathrm{C}\right)\left(\mathrm{T}_{\mathrm{a}}\right)$ dan kelembaban udara ( $\mathrm{kg} / \mathrm{kg}$ udara kering)

5. GCV bahan bakar (kkal/kg)

6. Persentase bahan yang tidak dapat terbakar dalam abu (untuk bahan bakar padat )

7. GCV abu (kkal/kg) (untuk bahan bakar padat)

Tahap-tahap perhitungan efisiensi boiler menggunakan metode tidak langsung adalah sebagai berikut

Tahap 1: Menghitung kebutuhan udara teoritis

$$
=\frac{(11,43 \times \mathrm{C})+\left\{34,5 \times\left(\mathrm{H}_{2}-\frac{\mathrm{O}_{2}}{8}\right)\right\}+(4,32 \times \mathrm{S})}{100}\left(\frac{\mathrm{kg}}{\mathrm{kg}} \text { bahan bakar }\right)
$$

Tahap 2: menghitung persen kelebihan udara yang dipasok (EA)

$$
=\frac{\% O_{2} \times 100}{\left(21-\% O_{2}\right)}
$$

Tahap 3: Menghitung massa udara sebenarnya yang dipasok (AAS)

$=\left\{\left(1+\frac{E A}{100}\right)\right.$

$\times$ Udara Teoritis $\} \quad\left(\frac{k g}{k g}\right.$ bahan bakar $)$

Tahap 4: Memperkirakan seluruh kehilangan panas

(4.1) Persentase kehilangan panas yang diakibatkan oleh gas buang yang kering ( $\mathrm{q} 1$ )

$=\frac{\mathrm{m} \times \mathrm{Cp} \times(\mathrm{Tf}-\mathrm{Ta}) \times 100}{\text { GCV Bahan bakar }}$

Dimana:

- $\mathrm{m}=$ massa gas buang kering $(\mathrm{kg} / \mathrm{kg}$ bahan bakar)

- $\quad \mathrm{m}=$ (massa hasil pembakaran kering $/ \mathrm{kg}$ bahan bakar ) + (massa N2 dalam massa udara pasokan yang sebenarnya)

- $\mathrm{Cp}=$ Panas jenis gas buang $(0,23 \mathrm{kkal} / \mathrm{kg})$

- $\quad \mathrm{Tf}=$ Suhu gas buang $(\mathrm{oC})$

- $\mathrm{Ta}=$ Suhu ambien (oC)

- $\mathrm{GCV}=$ nilai $\mathrm{kalor}$ bahan bakar $(\mathrm{kkal} / \mathrm{kg})$
(4.2) Persen kehilanagan panas karena penguapan air yang terbentuk karena adanya $\mathrm{H}_{2}$ dalam bahan bakar (q2)

$=\frac{9 \times \mathrm{H} 2\{584+\mathrm{Cp}(\mathrm{Tf}-\mathrm{Ta})\}}{\text { GCV Bahan bakar }}$

Dimana:

- $\mathrm{H}_{2}=$ persen $\mathrm{H}_{2}$ dalam $1 \mathrm{~kg}$ bahan bakar

- $\mathrm{Cp}=$ panas jenis steam lewat jenuh / superheated steam $(0,45 \mathrm{kkal} / \mathrm{kg})$

- $\mathrm{Tf}=$ Suhu gas buang $\left({ }^{\circ} \mathrm{C}\right)$

- $\mathrm{Ta}=$ Suhu ambien $\left({ }^{\circ} \mathrm{C}\right)$

- $\mathrm{GCV}=$ nilai $\mathrm{kalor}$ bahan bakar $(\mathrm{kkal} / \mathrm{kg})$

(4.3) Persen kehilangan panas karena penguapan kadar air dalam bahan bakar (q3)

$$
=\frac{\mathrm{M}\{584+\mathrm{Cp}(\mathrm{Tf}-\mathrm{Ta})\}}{\text { GCV Bahan bakar }}
$$

Dimana:

- $\quad M=$ persen kadar air dalam $1 \mathrm{~kg}$ bahan bakar

- $\mathrm{Cp}=$ panas jenis steam lewat jenuh/ superheated steam $(0,45 \mathrm{kkal} / \mathrm{kg})$

- $\mathrm{Tf}=$ Suhu gas buang $(\mathrm{oC})$

- $\mathrm{Ta}=$ Suhu ambien $(\mathrm{oC})$

- $\mathrm{GCV}=$ nilai kalor bahan bakar $(\mathrm{kkal} / \mathrm{kg})$

(4.4) Persen kehilangan panas karena kadar air dalam udara (q4)

$=\frac{\text { AAS } x \text { factor kelembaban } \times \mathrm{Cp}(\mathrm{Tf}-\mathrm{Ta})\} \times 100}{\text { GCV Bahan Bakar }}$

Dimana:

- $\mathrm{Cp}=$ panas jenis steam lewat jenuh / superheated steam $(0,45 \mathrm{kkal} / \mathrm{kg})$

- $\mathrm{Tf}=$ Suhu gas buang $(\mathrm{oC})$

- $\mathrm{Ta}=$ Suhu ambien $(\mathrm{oC})$

- $\mathrm{GCV}=$ nilai $\mathrm{kalor}$ bahan bakar $(\mathrm{kkal} / \mathrm{kg})$

(4.5) Persen kehilangan panas karena bahan bakar yang tidak terbakar dalam abu terbang/fly ash (q5)

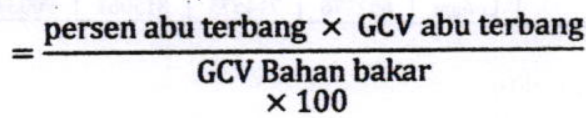

Dimana:

- $\mathrm{GCV}=$ nilai kalor bahan bakar $(\mathrm{kkal} / \mathrm{kg})$

- $\mathrm{GCV}=$ nilai $\mathrm{kalor}$ abu $(\mathrm{kkal} / \mathrm{kg})$ 
(4.6) Persen kehilangan panas karena bahan bakar yang tidak terbakar dalam abu bawah/ bottom ash (q6)

$$
=\frac{\text { persen abu bawah } \times \text { GCV abu bawah }}{\text { GCV Bahan bakar }}
$$

Dimana:

- $\mathrm{GCV}=$ nilai $\mathrm{kalor}$ bahan bakar $(\mathrm{kkal} / \mathrm{kg})$

- $\mathrm{GCV}=$ nilai $\mathrm{kalor}$ abu (kkal/kg)

(4.7) Persen kehilangan panas karena radiasi dan kehilangan lain yang tidak terhitung (q7)

Kehilangan radiasi dan konveksi aktual sulit dikaji sebab daya emisifitas permukaan yang beraneka ragam, kemiringan, pola aliran udara, dll. Pada boiler yang relatif kecil, dengn kapasitas $10 \mathrm{MW}$, kehilangan radiasi dan yang tak terhitung dapat mencapai 1 hingga 2 persen dari nilai kalor kotor bahan bakar, sementara pada boiler $500 \mathrm{MW}$ nilainya 0,2 hingga 1 persen. Kehilangan panas dapat diasumsikan secara tepat tergantung pada kondisi permukaan.

Tahap 5: Menghitung efisiensi boiler $(\eta)=100 \%-(q 1+q 2+q 3+q 4+q 5+q 6+$ q7)

\section{HASIL DAN PEMBAHASAN}

\section{Metode Langsung}

Berikut adalah data hasil perhitungan efisiensi boiler dengan menggunakan metode langsung.

Tabel.1 Efisiensi boiler dengan metode langsung

\begin{tabular}{|c|l|c|c|c|c|c|}
\hline \multirow{2}{*}{ No } & \multirow{2}{*}{} & \multirow{2}{*}{ Satuan } & \multicolumn{4}{|c|}{ Load/ Beban (\%) } \\
\cline { 4 - 7 } & Deskripsi & & 75 & 80 & 90 & 100 \\
\hline 1 & Efisiensi & $\%$ & 84,84 & 86,25 & 86,04 & 87,3 \\
\hline 2 & $\mathrm{mbb}$ & $\mathrm{kg} / \mathrm{jam}$ & 115000 & 124000 & 141000 & 153000 \\
\hline 3 & & $\mathrm{mg} / \mathrm{jam}$ & 652776 & 714573 & 815061 & 900376 \\
\hline
\end{tabular}

Hubungan Efisiensi terhadap beban generator diperlihatkan pada Gambar 1.

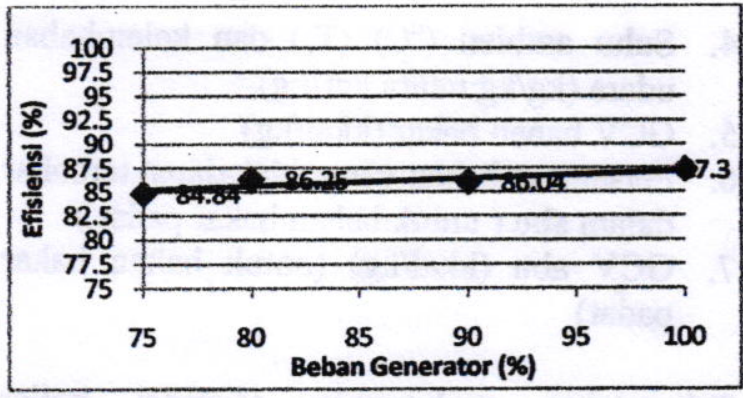

Gambar.1 Hubungan efisiensi boiler terhadap beban generator dengan metode langsung

Pada Tabel 1 dan Gambar 1 terlihat bahwa dengan menggunakan metode langsung ini didapatkan efisiensi boiler unit 2 pada beban 75\% (225 MW) adalah sebesar 84,84\%; Pada beban $80 \%$ (240 MW) sebesar 86,25\%; Sedangkan pada beban $90 \%$ (270 MW) sebesar $86,04 \%$; Serta pada beban maksimum (300 MW) efisiensinya sebesar $87,3 \%$. Dengan demikian terlihat bahwa efisiensi meningkat sesuai dengan peningkatan pembebanan dan selanjutnya konstan (stabil) pada beban $80 \%$ dan $90 \%$.

Dengan bertambahnya beban maka jumlah bahan bakar yang digunakan dan uap yang dihasilkan akan semakin besar. Seperti terlihat pada Tabel 1, konsumsi bahan bakar meningkat dari $115.000 \mathrm{~kg} / \mathrm{jam}$ pada beban $75 \%$ menjadi $153.000 \mathrm{~kg} / \mathrm{jam}$ pada beban maksimum. Selain itu uap yang dihasilkan juga meningkat dari $652.776 \mathrm{~kg} / \mathrm{jam}$ pada beban $75 \%$ menjadi $900.376 \mathrm{~kg} / \mathrm{jam}$ pada beban maksimum. Perbandingan antara massa uap yang dihasilkan terhadap jumlah bahan bakar yang digunakan (heat rate) semakin bertambah dengan semakin tingginya beban (Gambar 2).

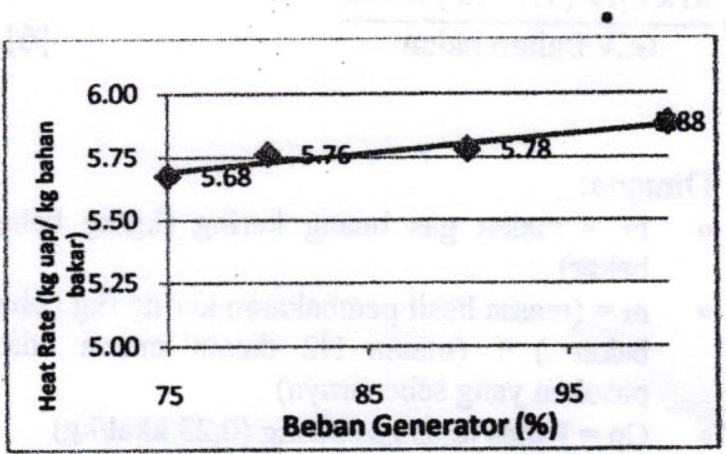

Gambar 2 Hubungan heat rate Boiler terhadap beban generator 


\section{Metode Tidak Langsung}

Tabel 2 merupakan hasil perhitungan efisiensi dengan metode tidak langsung.

Tabel.2 Efisiensi boiler dengan metode tidak langsung

\begin{tabular}{|c|l|c|c|c|c|c|}
\hline \multirow{2}{*}{$\begin{array}{l}\text { N } \\
0\end{array}$} & \multicolumn{1}{|c|}{ Deskripsi } & \multirow{2}{*}{$\begin{array}{c}\text { Sat } \\
\text { uan }\end{array}$} & \multicolumn{4}{|c|}{ Load/ Beban (\%) } \\
\cline { 4 - 7 } 1 & Efisiensi & $\%$ & 84,53 & 84,51 & 85,09 & 85,05 \\
\hline 2 & $\begin{array}{l}\text { Kehilangan panas } \\
\text { akibat gas buang }\end{array}$ & $\%$ & 7,37 & 7,36 & 6,81 & 6,87 \\
\hline 3 & $\begin{array}{l}\text { Kehilangan panas } \\
\text { akibat penguapan } \\
\text { air yang terbentuk } \\
\text { karena hidrogen } \\
\text { dalam bahan } \\
\text { bakar }\end{array}$ & $\%$ & 3,9 & 3,92 & 3,91 & 3,9 \\
\hline 4 & $\begin{array}{l}\text { Kehilangan panas } \\
\text { akibat penguapan } \\
\text { air dalam bahan } \\
\text { bakar }\end{array}$ & $\%$ & 3,33 & 3,34 & 3,33 & 3,32 \\
\hline & $\begin{array}{l}\text { Kehilangan panas } \\
\text { akibat air dalam } \\
\text { udara }\end{array}$ & $\%$ & 0,17 & 0,17 & 0,16 & 0,16 \\
\hline 6 & $\begin{array}{l}\text { Kehilangan panas } \\
\text { akibat radiasi dan } \\
\text { kehilangan lain yg } \\
\text { tak Terhitung }\end{array}$ & $\%$ & 0,7 & 0,7 & 0,7 & 0,7 \\
\hline
\end{tabular}

Gambar 3 menunjukan hubungan antara efisiensi dan beban generator dengan metode tidak langsung. Pada Gambar tersebut, efisiensi boiler dengan menggunakan metode tidak langsung besarnya relatif stabil yaitu sekitar $84,5 \%$ sampai $85 \%$ pada beban generator $75 \%$ sampai $100 \%$.

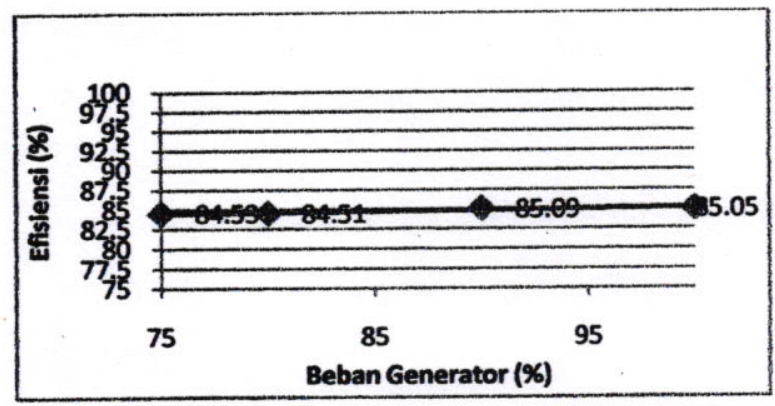

Gambar 3 Hubungan efisiensi boiler terhadap beban generator dengan metode tidak langsung

Kehilangan panas pada boiler paling besar diakibatkan oleh gas buang yaitu sekitar $6,81 \%$ - 7,37\%; Kehilangan panas paling kecil diakibatkan oleh kandungan air pada udara pembakaran yang besarnya $0,16 \%-0,17 \%$; Kehilangan panas yang diakibatkan penguapan air yang terbentuk karena adanya hidrogen pada bahan bakar adalah sekitar $3,9 \%$;
Kehilangan panas karena kandungan air pada bahan bakar yaitu sebesar 3,3\%; Dan kehilangan panas diakibatkan radiasi dan kehilangan yang tak terhitung besarnya adalah $0,7 \%$.

\section{Perbandingan efisiensi boiler dengan data disain dan komisioning}

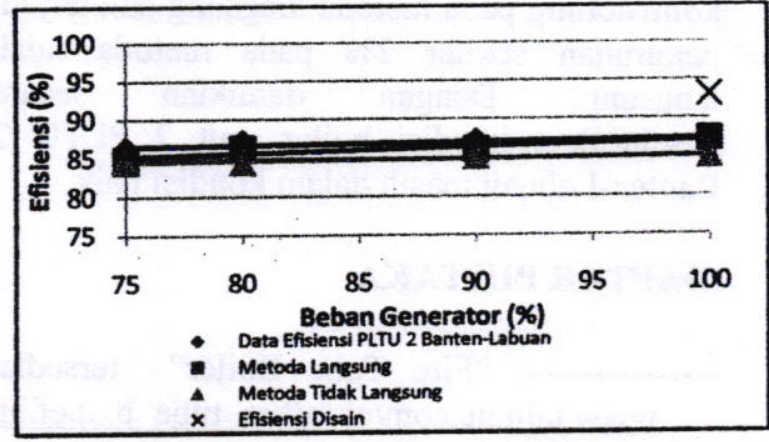

Gambar.4 Perbandingan efisiensi boiler dengan data disain dan komisioning

Berdasarkan hasil perhitungan efisiensi boiler unit 2 PLTU 2 Banten-Labuan seperti pada Gambar 4, besarnya efisiensi boiler dengan menggunakan metode langsung nilainya lebih tinggi jika dibandingkan dengan metode tidak langsung. Jika dibandingkan dengan data disain (93,1\% pada beban maksimum), efisiensi boiler unit 2 PLTU Labuan masih lebih rendah dengan selisih sekitar $6 \%$ pada metoda langsung dan $8 \%$ pada metoda tidak langsung. Sedangkan jika dibandingkan dengan data komisioning pada tahun 1994 (87,2\% pada beban maksimum), maka efisiensi boiler ini masih mendekati data komisioning tersebut pada metoda langsung dan terjadi penurunan sekitar $2 \%$ pada metoda tidak langsung.

\section{KESIMPULAN}

Efisiensi boiler unit 2 PLTU 2 Banten-Labuan pada metode langsung lebih besar dibanding pada metode tidak langsung. Pada metode langsung, efisiensi boiler semakin meningkat dengan meningkatnya beban generator dan cenderung stabil mulai beban $80 \%$ sampai $100 \%$. Efisiensi boiler dengan metode langsung pada beban maksimum (300 MW) adalah $87,3 \%$. Sedangkan dengan metode tidak langsung, efisiensi boiler relatif konstan sekitar $84,5 \%$ pada beban mulai $75 \%$ sampai beban $100 \%$. 
Jika dibandingkan dengan data disain $(93,1 \%$ pada beban maksimum), efisiensi boiler masih lebih rendah dengan selisih sekitar $6 \%$ pada metoda langsung dan $8 \%$ pada metoda tidak langsung. Sedangkan jika dibandingkan dengan data komisioning pada tahun 1994 (87,2\% pada beban maksimum), maka efisiensi boiler ini masih mendekati data komisioning pada metoda langsung dan terjadi penurunan sekitar $2 \%$ pada metoda tidak langsung. Dengan demikian secara keseluruhan kondisi boiler unit 2 PLTU 2 Banten-Labuan masih dalam kondisi baik.

\section{DAFTAR PUSTAKA}

"Fire Tube Boiler" tersedia: www.taijune.com/en/p/fire tube b...hef.ht $\mathrm{ml}$ (17 Oktober 2010)

"Horizontal Boiler" tersedia: www.alkazemco.com/eng_pages/steam.ht m (17 Oktober 2010) "Water Tube Boiler" tersedia: www.turbodradial.com/new page 1.htm (17 Oktober 2010)

Dongfang Boiler Group Co., Ltd. 2008. Boiler Spesification. Zigong-Sichuan.

El-Wakil, M.M. 1984. Power Plant Technology. Singapore: McGraw-Hill Book Co. .

Maridjo. 2005. Pembangkit listrik Tenaga Thermal (modul). Bandung: Politeknik Negeri Bandung.

Muin, Syamsir A. 1988. Pesawat-Pesawat Konversi Energi. Jakarta: Rajawali Pers.

Rianto, Bambang. "Pengenalan Dasar Unit Pembangkit".

UNEP. 2006. "Boiler and Thermic Fluid Heater"tersedia: www.energyefficiencyasia. org. (22 Juli 2010). 